\title{
Formulação do fungo Coniothyrium minitans para controle do mofo-branco causado por Sclerotinia sclerotiorum
}

\author{
Alex Moretini(1) e Itamar Soares de Melo(1) \\ (1)Embrapa Meio Ambiente, Caixa Postal 69, CEP 13820-000 Jaguariúna, SP. E-mail: alex@cnpma.embrapa.br, itamar@cnpma.embrapa.br
}

\begin{abstract}
Resumo - O fungo Sclerotinia sclerotiorum, agente causal do mofo-branco, tem controle dificultado pela longevidade de seus escleródios no solo. Uma estratégia alternativa de controle é o uso do fungo antagonista Coniothyrium minitans, que parasita os escleródios de $S$. sclerotiorum e reduz a incidência da doença. O objetivo deste trabalho foi desenvolver uma formulação com C. minitans capaz de controlar o mofo-branco. Para tanto, picnídios deste fungo foram encapsulados com diferentes polímeros (alginato de sódio e pectina cítrica), caulim e substratos naturais (farinha de trigo e celulose). Das combinações obtidas, a formulação que continha $0,5 \%$ de alginato, $1,5 \%$ de celulose e $5 \%$ de caulim apresentou os melhores resultados quanto à viabilidade do fungo e controle da doença. Os grânulos da formulação armazenados a $4^{\circ} \mathrm{C}$ apresentaram $100 \%$ de viabilidade do fungo. Nos grânulos armazenados a $28^{\circ} \mathrm{C}$, o fungo perdeu capacidade de crescer após os primeiros dois meses. O fungo formulado foi capaz de esporular sobre os grânulos incubados em meio de cultura BDA e no solo, como também foi capaz de reduzir a incidência da doença.
\end{abstract}

Termos para indexação: controle biológico, fitopatógenos, alface, alginato.

\section{Formulation of Coniothyrium minitans for biocontrol of white mold caused by Sclerotinia sclerotiorum}

\begin{abstract}
Sclerotinia sclerotiorum, causal agent of white mold, maintains its resistant structures viable for many years in the soil, and its control is difficult. An alternative method for controlling it is the use of Coniothyrium minitans, an antagonistic fungus efficient in attacking the sclerotia. The objective of this work was to develop a method to encapsulate picnidia of $C$. minitans to control the white mold, using different polymers, such as alginate and pectin supplemented with wheat flour or cellulose and kaolin. Picnidia of $C$. minitans formulated in alginate $0.5 \%$, cellulose $1.5 \%$, and kaolin $5 \%$ survived better at 4 than at $28^{\circ} \mathrm{C}$ when stored during two months. After this period, only the formulation stored at $4^{\circ} \mathrm{C}$ maintained its viability. When the formulation was stored at $28^{\circ} \mathrm{C}$, the fungus lost its ability to grow after two months. The fungus formulated grew abundantly on the pellets when they were inoculated on PDA. They also reduced completely the disease incidence in infested soil.
\end{abstract}

Index terms: biological control, phytopathogens, lettuce, alginate.

\section{Introdução}

A principal característica das formulações de agentes de controle biológico é favorecer a atividade do antagonista na interação patógeno-antagonista. Em geral, formulação é a maneira de apresentar o ingrediente ativo em uma forma física mais efetiva com respeito à atividade biológica, estocagem e aplicação. O material a ser utilizado nas formulações não deve ser tóxico, deve ser biodegradável, de fácil manuseio e possuir uniformidade. Autilização de suplementos na composição de formulações já foi estudada por outros autores como Papavizas et al. (1987), Salgado (1993) e Lewis et al. (1996).
Nos últimos anos, a literatura científica tem veiculado uma série de referências sobre interações sinergísticas vantajosas, decorrentes de combinações de misturas de formulações e microrganismos. Estudos em condições controladas demonstram que algumas combinações de bactérias ou fungos permitem maior disponibilidade de nutrientes, remoção de substâncias tóxicas do solo e estímulo na promoção de crescimento de plantas (Bashan, 1998). A título de exemplo citam-se benefícios como a maior atividade na fixação biológica de nitrogênio (Bashan \& Holguin, 1997), maior aporte de nutrientes à planta com inoculação, com N, P e outros minerais (Alagawadi \& Gaur, 1992; Bashan \& Holguin, 1997). 
Atualmente, uma opção nas pesquisas com formulações de organismos úteis usados na agricultura tem sido o alginato de sódio. Trata-se de um polissacarídeo solúvel em água, que é extraído de várias espécies de algas. Utilizado como aditivo em alguns alimentos industrializados e como material de moldagem em odontologia, o alginato de sódio não apresenta riscos de toxidez ao microrganismo formulado nem ao homem (Salgado, 1993).

A técnica de utilização do alginato de sódio se baseia na formação de um gel a partir de uma reação que ocorre entre certos cátions metálicos, tais como cálcio $\left(\mathrm{Ca}^{2+}\right)$, e solução aquosa de alginato de sódio. O gel é bioquimicamente inerte e possui uma porosidade que é dependente do tipo de alginato e do íon metálico utilizado.

$\mathrm{Na}$ busca de formulações mais eficientes para tratamento de solo, o alginato de sódio tem sido utilizado no preparo de grânulos com micélio e conídios de fungos, tanto para controle de plantas daninhas (Walker \& Connick Junior, 1983) como para o controle de patógenos de plantas (Fravel et al., 1985), entre eles: Alternaria cassiae, A. macrospora, Fusarium lateritium, Colletotrichum malvacearum, Talaromyces flavus, Trichoderma viride, Gliocadium virens e Coniothyrium minitans.

A aplicação de formulações granuladas ao solo tem favorecido a disseminação de fungos, na rizosfera das plantas, e o controle efetivo de patógenos que atacam as raízes. No entanto, a falta de formulações adequadas tem limitado o desenvolvimento de estratégias de controle biológico. O patógeno S. sclerotiorum apresenta ampla ocorrência em todo o mundo, com, pelo menos, 408 espécies de plantas hospedeiras (Boland \& Hall, 1994). Esse fungo é difícil de ser controlado em razão da agressividade, dispersão e a longa resistência dos escleródios no solo (Huang, 1980). Existem, porém, mais de 30 espécies de fungos e de bactérias com efeitos antagônicos ao Sclerotinia sp., os quais parasitam escleródios e previnem sua formação, ou reduzem a germinação carpogênica e, com isso, acarretam uma redução do potencial de inóculo. Entre os fungos antagonistas a esse patógeno encontram-se: Trichoderma sp. (Davet, 1988); Gliocladium roseun (Phillips, 1986) e C. minitans (Huang, 1980; Adams, 1989).

Na Europa, C. minitans é usado no controle do mofobranco em diversas áreas, controlando até $78 \%$ da doença (Fokkema et al., 1992). Embora haja diversos relatos sobre a eficiência do uso de $C$. minitans no controle de $S$. scletiorum em diversas culturas agrícolas
(Turner \& Tribe, 1976; Ahmed \& Tribe, 1977; Huang, 1980; Tu, 1984; Diamantopoulou et al., 2000; Whipps \& Budge, 2000), não existem trabalhos sobre formulações granuladas desse fungo para aplicação no solo. $\mathrm{O}$ sucesso de formulações granuladas, para uso no biocontrole, está relacionado à composição dos grânulos, tipo de propágulo e concentração de inóculo, tipo de carregador, dosagem e método de aplicação, e aos fatores ambientais que interferem nas interações patógeno-antagonista.

O objetivo deste trabalho foi desenvolver uma formulação granulada, à base de alginato de sódio, tendo como ingrediente ativo o fungo C. minitans, capaz de manter-se viável e eficiente quanto à ação hiperparasítica e ao controle biológico de Sclerotinia sclerotiorum.

\section{Material e Métodos}

Uma linhagem mutante de Coniothyrium minitans (CM4b), eficiente no controle de S. sclerotiorum e resistente ao fungicida iprodione, pertencente ao Banco de Recursos Genéticos Microbianos da Embrapa Meio Ambiente, foi utilizada neste trabalho.

Picnídios de C. minitans foram produzidos em BDA (batata-dextrose-ágar), por 15 dias a $26^{\circ} \mathrm{C}$, no escuro. Para encapsulamento dos picnídios, empregou-se a metodologia proposta por Sanhueza \& Melo (1995), com modificações, que corresponderam à adição de celulose ou de farelo de trigo como fontes nutricionais. A formulação consistiu no uso de dois polímeros: alginato de sódio e pectina cítrica. O caulim foi utilizado como carregador, em concentrações que variaram de 0,5 a $10 \%$.

$\mathrm{Na}$ produção dos géis, utilizou-se uma bomba peristáltica, e as misturas foram gotejadas separadamente numa solução de $\mathrm{CaCl}_{2} 2 \mathrm{M}$. Os géis, mantidos por 30 min nessa solução, foram lavados em água destilada esterilizada e secados a $30^{\circ} \mathrm{C}$ em estufa com circulação forçada de ar.

A avaliação das formulações obedeceu aos seguintes critérios: formação dos grânulos, quando em contato com a solução gelificante, e capacidade de germinação dos propágulos fúngicos, quando imobilizados.

As formulações, depois de secadas, foram estocadas separadamente, a $4^{\circ} \mathrm{C}$ e a $28^{\circ} \mathrm{C}$; a avaliação da viabilidade do fungo foi examinada periodicamente, por 14 meses. Para isso, 20 grânulos foram plaqueados em cada placa de Petri com BDA, suplementado com 
iprodione $(10 \mu \mathrm{g} \mathrm{mL}-1)$, e incubados a $26^{\circ} \mathrm{C}$, por 48 horas. O iprodione foi utilizado em razão da resistência da linhagem fúngica a este fungicida e para evitar possíveis contaminações. Considerou-se viável o grânulo que apresentou germinação fúngica. Estas observações foram comprovadas por meio de microscópio eletrônico de varredura. Adicionalmente, avaliou-se a capacidade do fungo de hiperparasitar $C$. minitans, cujo ensaio foi realizado do seguinte modo: discos de BDA com S. sclerotiorum foram colocados na extremidade de cada placa de Petri; dois dias depois, um grânulo com C. minitans foi colocado na outra extremidade da placa. Após contato com o antagonista, os escleródios de S. sclerotiorum foram colhidos e processados para visualização em microscopia eletrônica de varredura.

Grânulos contendo picnídios de C. minitans e escleródios de $S$. sclerotiorum parasitados pelo antagonista foram fixados em glutaraldeido $2 \%$ por 3 horas, lavados em tampão fosfato de sódio $0,1 \mathrm{M}$ e pósfixados em tetróxido de ósmio $1 \%$ por $30 \mathrm{~min}$ e, novamente lavados com o mesmo tampão. Após esse processo, procedeu-se à desidratação, utilizando-se uma série crescente de acetona $(15,20,25,50,70,80,90$ e $100 \%)$. As amostras foram submetidas à secagem até o ponto crítico, metalizadas com ouro por $3 \mathrm{~min}$ a 25 miliampere, e observadas em um microscópio de varredura "field emission", modelo Gemini 982.

Nos ensaios de biocontrole, o solo utilizado foi o de mata nativa, cujas características químicas foram: $\mathrm{pH}$ em $\mathrm{CaCl}_{2}, 3,6$; matéria orgânica, $30 \mathrm{~g} \mathrm{dm}^{-3} ; \mathrm{P}, 6 \mathrm{mg} \mathrm{dm}^{-3}$; $\mathrm{K}, \mathrm{Ca}$ e $\mathrm{Mg}, 1,6,1$ e $2 \mathrm{mmol} \mathrm{dm}^{-3}$, respectivamente; $\mathrm{H}+\mathrm{Al}$ (acidez potencial), $121 \mathrm{mmol} \mathrm{dm}^{-3}$; soma de base trocáveis, 4,6 $\mathrm{mmol} \mathrm{dm}^{-3}$; capacidade de trocas de cátions, $125,6 \mathrm{mmol} \mathrm{dm}^{-3}$; e saturação por bases, $4 \mathrm{mmol} \mathrm{dm}^{-3}$. As análises de solo foram realizadas no Departamento de Ciências do Solo da Escola Superior de Agricultura Luiz de Queiroz, Piracicaba, SP. O solo autoclavado por $30 \mathrm{~min}$, por três vezes consecutivas, com intervalos de 12 horas, foi usado para preencher vasos de plástico $(15 \times 17 \mathrm{~cm})$. Como hospedeiro suscetível ao S. sclerotiorum, foram utilizadas plantas de alface.

Os tratamentos foram: T1 (controle), plantas de alface sem inoculação; T2, plantas com inoculação de S. sclerotiorum; T3, plantas com inoculação de S. sclerotiorum e C. minitans formulado (10 g por vaso); T4, plantas com inoculação de S. sclerotiorum, C. minitans formulado ( $5 \mathrm{~g}$ por vaso) e iprodione $(5 \mu \mathrm{L}$ por vaso); T5, plantas com inoculação de $S$. sclerotiorum e iprodione (5 $\mu \mathrm{L}$ por vaso).
A infestação do solo com o patógeno se deu por meio de escleródios, produzidos em meio semi-sólido de aveiaágar (60 g de aveia e $15 \mathrm{~g}$ de ágar), por 15 dias. Os vasos receberam escleródios e três plântulas de alface, e foram mantidos em casa de vegetação pelo período de 40 dias, com temperaturas entre 20 e $25^{\circ} \mathrm{C}$. A avaliação da reação ao patógeno foi feita pela contagem do número de plantas mortas.

O teste de Tukey, a 5\% de probabilidade, foi aplicado com o auxílio do aplicativo Statistica (StatSoft, Tulsa OK, EUA), para a comparação das médias do número de plantas vivas.

\section{Resultados e Discussão}

Os produtos usados nas formulações tiveram resultados diferenciados com relação à uniformidade dos grânulos, sobrevivência e viabilidade do fungo. As formulações com 0,5 e $1 \%$ de alginato de sódio, $1,5 \%$ de celulose e $5 \%$ de caulim (Tabela 1) apresentaram as

Tabela 1. Relação da quantidade (g) dos produtos utilizados na produção de grânulos para formulação do fungo Coniothyrium minitans.

\begin{tabular}{cccccc}
\hline Alginato & Celulose & Pectina & $\begin{array}{c}\text { Farinha de } \\
\text { trigo }\end{array}$ & Caulim & Avaliação $^{(1)}$ \\
\hline 1 & 1,5 & 0 & 0 & 5 & 5 \\
0,5 & 1,5 & 0 & 0 & 5 & 5 \\
1 & 0 & 0 & 1,5 & 5 & 4 \\
1,5 & 0 & 0 & 1,5 & 3 & 4 \\
0,5 & 0 & 0 & 0 & 5 & 3 \\
0,5 & 0 & 0 & 1 & 5 & 3 \\
0,5 & 1 & 0 & 0 & 5 & 3 \\
0,5 & 2 & 0 & 0 & 5 & 3 \\
0,5 & 2 & 0 & 0 & 4 & 3 \\
0,5 & 3 & 0 & 0 & 10 & 3 \\
0,5 & 3 & 0 & 0 & 0 & 3 \\
0,5 & 0 & 1,5 & 0 & 2,5 & 2 \\
0,5 & 0 & 1,5 & 0 & 3 & 2 \\
0,5 & 0 & 3 & 0 & 10 & 2 \\
0,5 & 0 & 3 & 0 & 0 & 2 \\
0,5 & 1 & 0 & 0 & 2,5 & 2 \\
0,5 & 2 & 0 & 0 & 2,5 & 2 \\
0,25 & 1,5 & 0 & 0 & 5 & 2 \\
0 & 3 & 3 & 0 & 10 & 1 \\
0 & 3 & 3 & 0 & 0 & 1 \\
\hline
\end{tabular}

(1) Avaliação realizada com base numa escala de notas de 1 a 5 , considerando a formação dos grânulos, a viabilidade fúngica, a meia-vida de prateleira e a eficiência de biocontrole: 1: não formação dos géis quando em contato com a solução de $\mathrm{CaCl}_{2} ; 2$ : os grânulos são formados, mas irregulares quando secos; 3: os grânulos são formados, com estruturas regulares, mas com uma redução (abaixo de $20 \%$ ) na viabilidade do fungo; 4: grânulos uniformes, viabilidade superior a 70\%, mas crescimento fúngico extremamente lento; 5: formulação com $100 \%$ de viabilidade, com crescimento fúngico rápido. 
melhores características quanto à formação e morfologia dos géis e viabilidade do fungo.

A adição de celulose à formulação possibilitou maior uniformidade dos grânulos e maior viabilidade do fungo. A Figura 1 mostra o fungo, formulado em alginato, celulose e caulim, germinando após 10 dias de cultivo em meio BDA. Por outro lado, a suplementação com farinha de trigo não favoreceu a uniformidade morfológica dos grânulos. Papavizas et al. (1987)
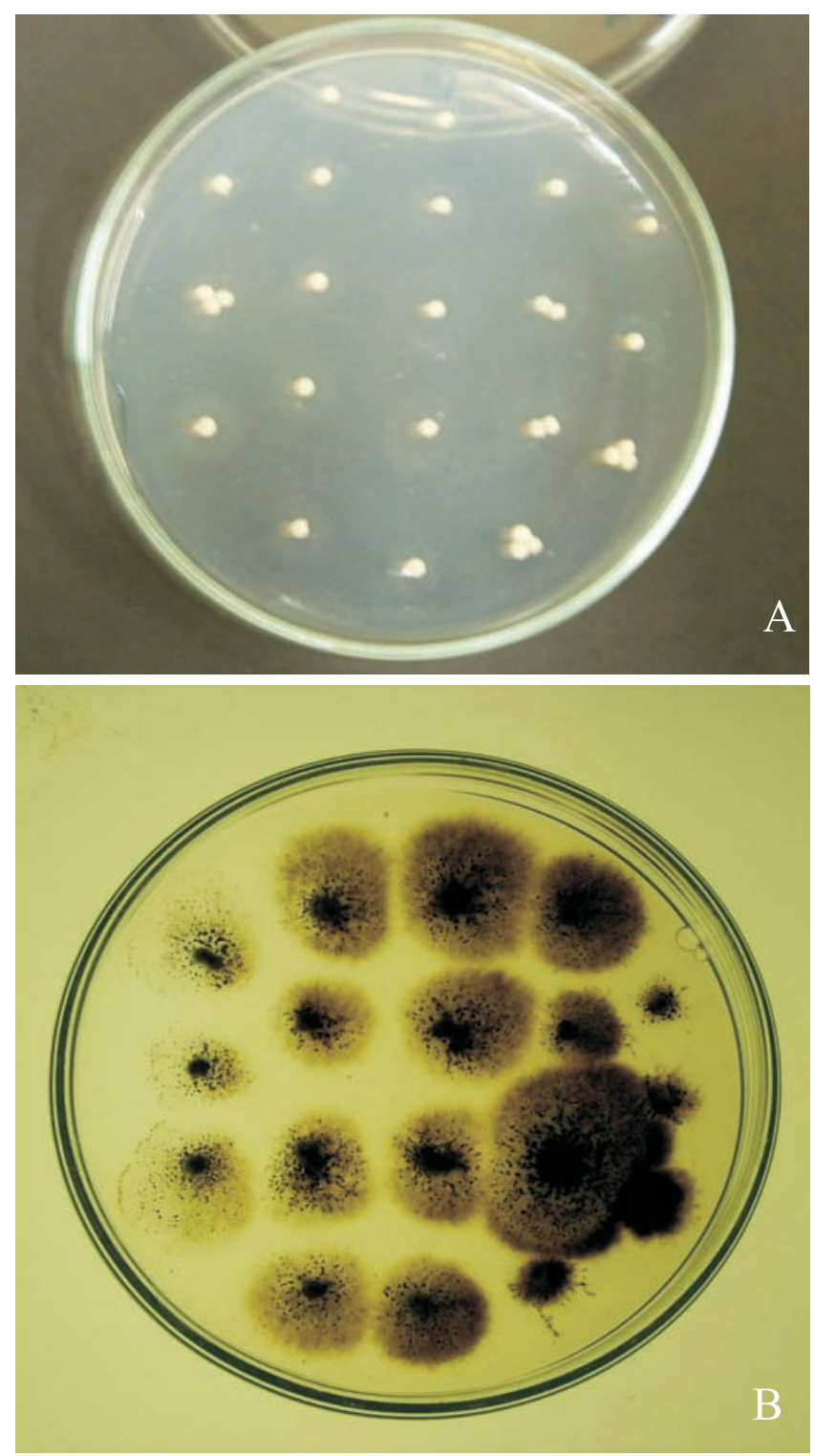

Figura 1. Grânulos de alginato de sódio, celulose e caulim apresentando o desenvolvimento do Coniothyrium minitans em meio de cultivo BDA, com 5 (A) e 10 dias (B) de inoculação. A placa B mostra a germinação miceliana típica do fungo. observaram aumento na produção conidial de vários fungos, com a adição de farinha de trigo na composição dos grânulos.

A avaliação do período de estocagem dos grânulos produzidos neste trabalho foi feita a 4 e $28^{\circ} \mathrm{C}$. Os grânulos estocados a $4^{\circ} \mathrm{C}$ apresentaram $100 \%$ de viabilidade, mesmo depois de estocados por 14 meses, enquanto aqueles estocados a $28^{\circ} \mathrm{C}$ apresentaram diminuição da viabilidade no segundo mês de armazenamento, e nos meses seguintes não apresentaram nenhuma viabilidade (Tabela 2). Walker \& Connick Junior (1983), ao utilizar uma formulação à base de alginato e caulim, observaram que estes permaneceram esféricos e que os fungos esporularam rapidamente após armazenamento a 4 ou $25^{\circ} \mathrm{C}$, por seis a oito meses; em observações de campo, os fungos esporularam rapidamente sob umidade adequada. Com base nesses trabalhos, concluiu-se que a formulação com alginato de sódio pode facilitar a distribuição de agentes biológicos e a produção de inóculos de fitopatógenos utilizados na avaliação de resistência de plantas a doenças.

Salgado (1993) relatou a longevidade de Arthrobotrys conoides peletizados e armazenados por 60 dias a $4^{\circ} \mathrm{C}$, e verificou que o fungo apresentou recuperação de aproximadamente $100 \%$, um ano após a produção dos grânulos. Fravel et al. (1985) observaram que a longevidade dos microrganismos peletizados está associada ao tipo de microrganismo e tipo de esporo. Eles observaram um declínio de até $99,1 \%$ na viabilidade dos grânulos nas duas primeiras semanas.

A avaliação da reação de plantas de alface tratadas com a formulação à base de $C$. minitans quanto ao ataque de $S$. sclerotiorum demonstrou um controle total da doença (Figura 2). Do mesmo modo, a utilização da formulação e do fungicida iprodione, na concentração

Tabela 2. Viabilidade dos propágulos fúngicos nos grânulos armazenados em diferentes temperaturas.

\begin{tabular}{ccc}
\hline Temperatura $\left({ }^{\circ} \mathrm{C}\right)$ & Meses & Grânulos viáveis $(\%)$ \\
\hline 4 & 1 & 100 \\
& 2 & 100 \\
& 4 & 100 \\
& 14 & 100 \\
\hline 28 & 1 & 100 \\
& 2 & 80 \\
& 4 & 0 \\
14 & 0 \\
\hline
\end{tabular}


de $5 \mu \mathrm{L}$ reduziu a incidência da doença. $\mathrm{O}$ tratamento do solo com $10 \mu \mathrm{L}$ de iprodione, usado como produto eficiente no controle do mofo-branco, propiciou pleno controle do doença. Um menor controle do patógeno e, conseqüentemente, do mofo-branco, quando Coniothyrium e iprodione foram usados conjuntamente, pode ser explicado pelo enfraquecimento do fungo afetado pelo fungicida e, com isso, um menor desempenho no parasitismo dos escleródios. Salientase que a linhagem fúngica usada neste trabalho é resistente a doses extremamente baixas do fungicida iprodione. A adoção de métodos combinados de manejo de doenças de plantas tem sido estimulada pelos pesquisadores; principalmente os métodos que favorecem a microbiota antagonística natural. O uso de linhagens resistentes a determinado fungicida em combinação com doses reduzidas desse mesmo fungicida tem incrementado o controle de algumas doenças de plantas (Cook \& Baker, 1983). A utilização, neste trabalho, de uma linhagem de $C$. minitans $(\mathrm{CM} 4 \mathrm{~b})$ resistente a iprodione, contribuiu com o controle integrado do mofo-branco. A estratégia de utilização de

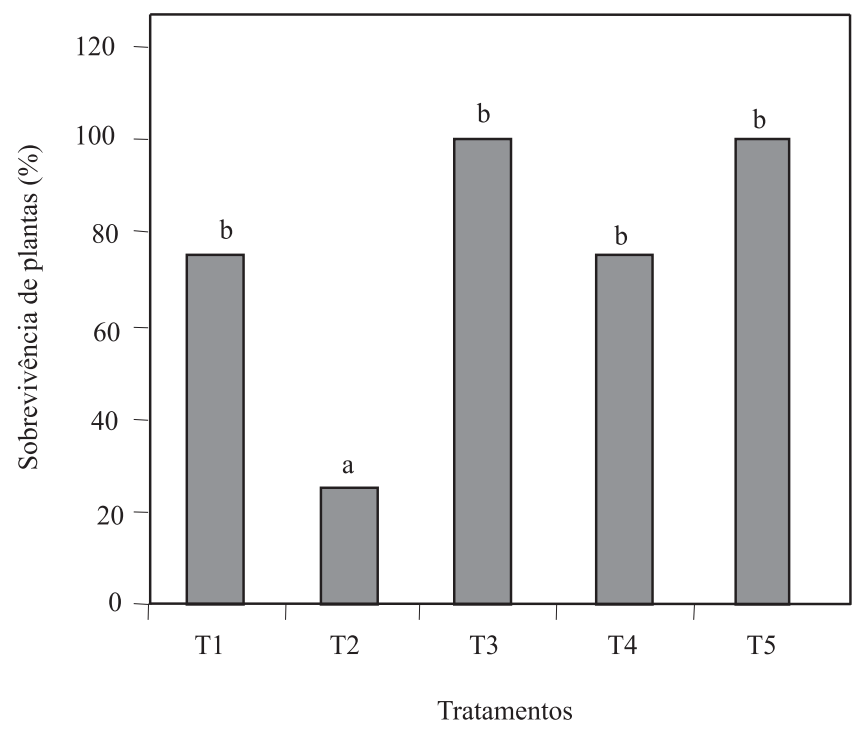

Figura 2. Sobrevivência de plantas de alface com inoculação de Sclerotinia sclerotiorum e tratadas com Coniothyrium minitans, formulado em alginato e iprodione. T1: controle (sem inoculação); T2: inoculação de S. sclerotiorum; T3: inoculação de S. sclerotiorum $+C$. minitans (10 g por vaso); T4: inoculação de S. sclerotiorum $+C$. minitans + iprodione (5 g por vaso); T5: inoculação de $S$. sclerotiorum e iprodione. Tratamentos com letras distintas diferem entre si pelo teste de Tukey, a 5\% de probabilidade.
C. minitans resistente facilitou a recuperação e o monitoramento do fungo no solo. Ficou demonstrado que o fungo antagonista $C$. minitans (CM4b) é eficiente no controle do mofo-branco, quando formulado com alginato, caulim e celulose.

O fungo formulado em alginato, caulim e celulose, cultivado em meio BDA, iniciou a germinação dos propágulos depois de 24 horas. A partir do sexto dia depois da inoculação, foi possível observar abundante massa micelial sobre os grânulos. A Figura 3 A mostra

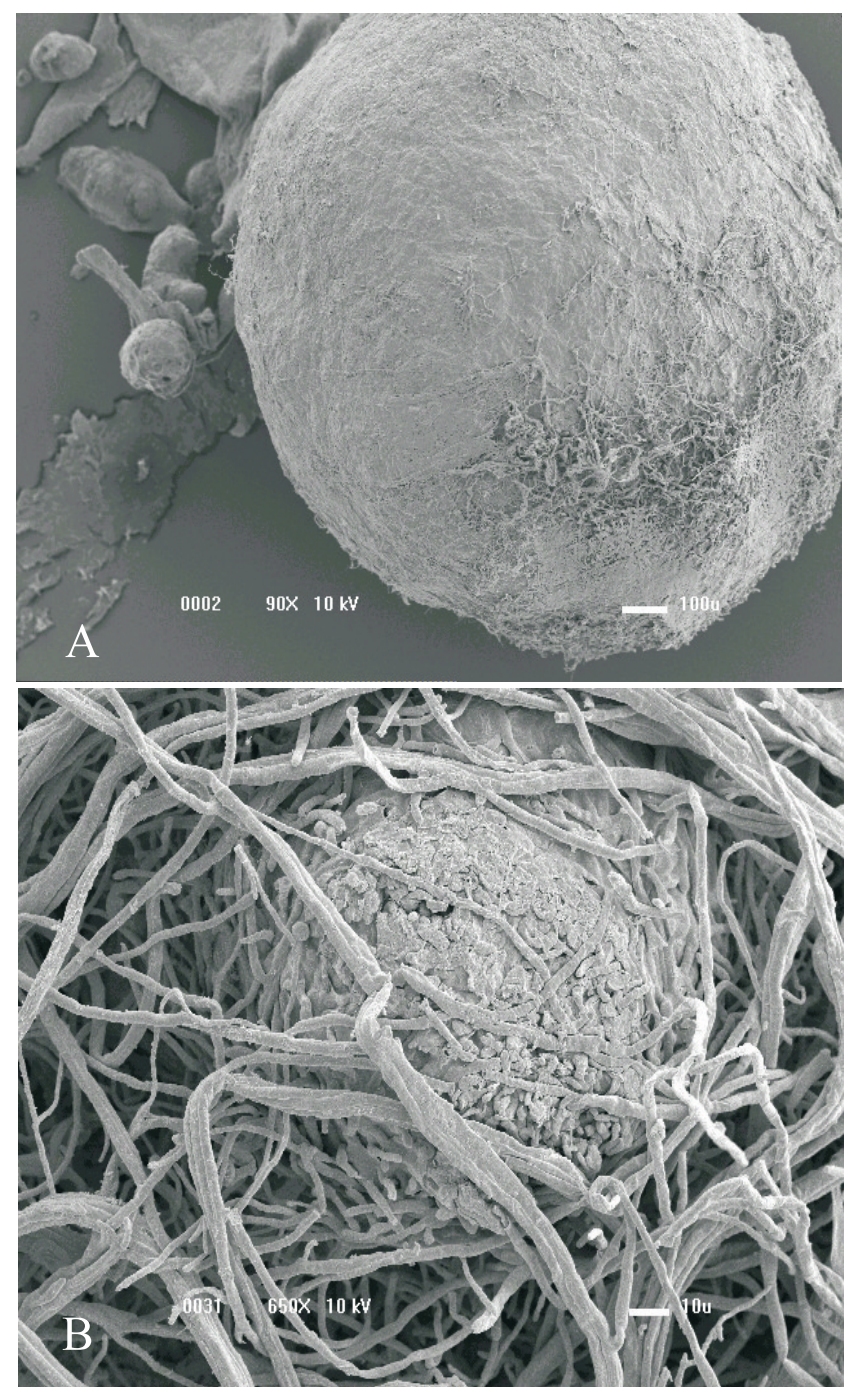

Figura 3. Desenvolvimento do Coniothyrium minitans em grânulos de alginato de sódio, celulose e caulim, observado em microscopia eletrônica de varredura. A imagem (A) mostra um grânulo 48 horas após a incubação, e a imagem (B) mostra um grânulo 72 horas após a incubação. 
o aspecto morfológico de um grânulo seco, e a Figura 3 B mostra a germinação de Coniothyrium, depois de 72 horas da incubação. Os grânulos depois da secagem apresentaram-se irregulares, com aspectos ovóides. Em ensaios prévios, visando a avaliar as melhores concentrações de alginato quanto à formação dos géis, verificou-se que a concentração de $2 \%$ desse polímero permite obter grânulos mais uniformes morfologicamente, lisos e regulares após a secagem. Outros autores também utilizaram $2 \%$ de alginato na obtenção de grânulos à base de fungos para uso no controle biológico (Fravel et al., 1985; Papavizas, 1987). Neste trabalho, a redução em $75 \%$ da quantidade desse polímero na formulação possibilitou a imobilização de picnídios de $C$. minitans, com alta viabilidade dos propágulos, depois de 14 meses de armazenagem. A redução da quantidade de alginato empregada nas formulações propicia redução significativa nos custos envolvidos, já que é um produto importado e altamente oneroso. Grânulos armazenados por dois meses foram, então, avaliados quanto à capacidade do fungo antagônico parasitar seu hospedeiro. A viabilidade do micoparasita foi extremamente alta, considerando-se que este colonizou completamente os escleródios de S. sclerotiorum (Figura 4). Ao avaliar a ação hiperparasítica desse mesmo antagonista contra S. sclerotiorum, Phillips \& Price (1983) e Tu (1984) mostraram que $C$. minitans cresceu intercelularmente e intracelularmente em escleródios de S. sclerotiorum.

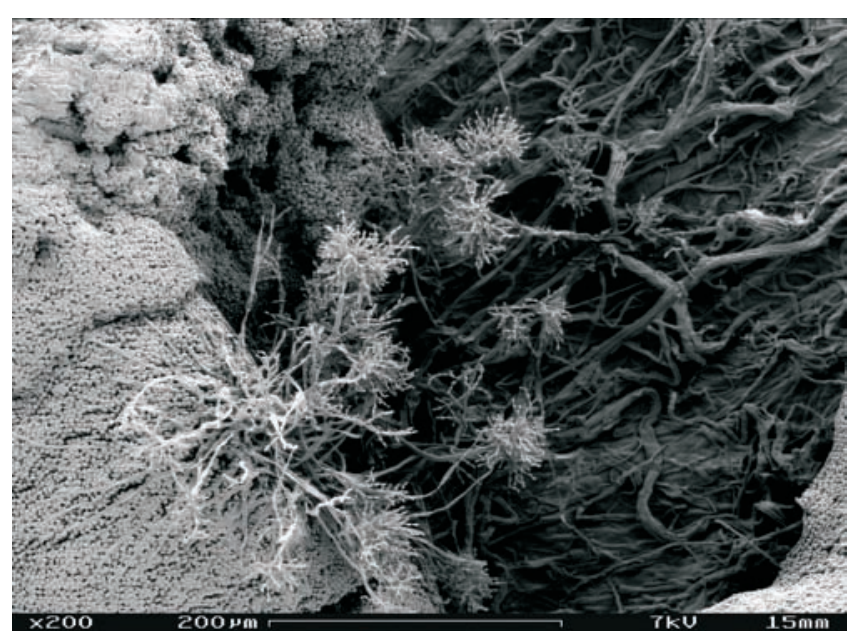

Figura 4. Parasitismo de Sclerotinia sclerotiorum por Coniothyrium minitans. A imagem mostra a colonização miceliana do antagonista sobre escleródios de $S$. sclerotiorum, sob microscopia eletrônica de varredura.

\section{Conclusões}

1. A formulação granulada, desenvolvida à base do fungo Coniothyrium minitans, com $0,5 \%$ de alginato de sódio, $1,5 \%$ de celulose e $5 \%$ de caulim, apresenta alto índice de viabilidade dos propágulos, quando armazenada a $4^{\circ} \mathrm{C}$ por um período de 14 meses.

2. Coniothyrium minitans, quando formulado com alginato e introduzido no solo, inibe o desenvolvimento do mofo-branco em alface.

\section{Referências}

ADAMS, P.B. Comparison of antagonists of Sclerotinia species. Phytopathology, v.79, p.1345-1347, 1989.

AHMED, A.H.M.; TRIBE, H.T. Biological control of white rot of onion (Sclerotium cepivorum) by Coniothyrium minitans. Plant Pathology, v.26, p.75-76, 1977.

ALAGAWADI, A.R.; GAUR, A.C. Inoculation of Azospirillum brasilense and phosphate-solubilizing bacteria on yield of sorghum [Sorghum bicolor (L.) Moench] in dry land. Tropical Agriculture, v.69, p.347-350, 1992.

BASHAN, Y. Inoculants of plant growth-promoting bacteria for use in agriculture. Biotechnology Advances, v.16, p.729-770, 1998.

BASHAN, Y.; HOLGUIN, G. Azospirillum-plant relations: environmental and physiological advances (1990-1996). Canadian Journal of Microbiology, v.43, p.103-121, 1997.

BOLAND, G.J.; HALL, R. Index of plant hosts of Sclerotinia sclerotiorum. Canadian Journal of Plant Pathology, v.16, p.93$108,1994$.

COOK, R.J.; BAKER, K.F. The nature and practice of biological control of plant pathogens. St. Paul: American Phytopathological Society, 1983. 539p.

DAVET, P. Criteria for selecting Trichoderma clones antagonistic to sclerotial fungi in soil. Bulletin OEPP, v.17, p.535-540, 1988.

DIAMANTOPOULOU, A.; LITKEI, J.; SKOPA, C.; CHRISTIAS, C. Effects of inhibitors of sclerotium formation on the sclerotial mycoparasite Coniothyrium minitans and its host Sclerotinia sclerotiorum. Mycological Research, v.104, p.1449-1452, 2000.

FOKKEMA, N.J.; GERLAGH, M.; KOHL, J. Biological control of Sclerotinia sclerotiorum and Botrytis spp. In: TJAMOS, E.C.; PAPAVIZAS, G.C.; COOK, R.J. Biological control of plant disease: progress and challenges for the future. New York: Plenum Press, 1992. p.267-271.

FRAVEL, D.R.; MAROIS, J.J.; LUMSDEN, R.D.; CONNICK, W.J. Encapsulation of potential biocontrol agents in an alginate-clay matrix. Phytopathology, v.75, p.774-777, 1985.

HUANG, H.C. Control of Sclerotinia wilt of sunflowers by hyperparasites. Canadian Journal of Plant Pathology, v.2, p.2632, 1980.

LEWIS, J.A.; LUMDSEN, R.D.; LOCKE, J.C. Biocontrol of damping-off diseases caused by Rhizoctonia solani and Pythium 
ultimum with alginate prills of Gliocladium virens, Trichoderma hamatum and various food bases. Biocontrol Science and Technology, v.6, p.163-173, 1996.

PAPAVIZAS, G.C.; FRAVEL, D.R.; LEWIS, J.A. Proliferation of Talaromyces flavus in soil and survival in alginate pellets. Phytopathology, v.77, p.131-136, 1987.

PHILLIPS, A.J.L. Carpogenic germination of sclerotia of Sclerotinia sclerotiorum: a review. Phytophylactica, v.19, p.279-283, 1986.

PHILLIPS, A.J.L.; PRICE, K. Structural aspect of the parasitism of sclerotia of Sclerotinia sclerotiorum (Lib.) de Bary by Coniothyrium minitans Campb. Phytopathology, v.107, p.193-203, 1983.

SALGADO, S.M.L. Formulação do fungo Arthrobotrys conoides em alginato de sódio para controle de fitonematóide. 1993. 37p. Dissertação (Mestrado) - Universidade Federal de Lavras, Lavras.

SANHUEZA, R.M.V.; MELO, I.S. Encapsulamento de microrganismos. In: MELO, I.S.; SANHUEZA, R.M.V. (Coord.).
Métodos de seleção de microrganismos antagônicos a fitopatógenos. Jaguariúna: Embrapa-CNPMA, 1995. v.1, p.60-63. (Embrapa-CNPMA. Documentos, 1).

TU, J.C. Mycoparasitism by Coniothyrium minitans on Sclerotinia sclerotiorum and its effect on sclerotial germination. Phytopathologische Zeitschrift, v.109, p.261-268, 1984.

TURNER, G.J.; TRIBE, H.T. On Coniothyrium minitans and its parasitism of Sclerotinia species. Transactions of the British Mycological Society, v.66, p.97-105, 1976.

WALKER, H.L.; CONNICK JUNIOR, W.J. Sodium alginate for production and formulation of mycoherbicides. Weed Science, v.31, p.335-338, 1983.

WHIPPS, J.M.; BUDGE, S.P. Effect of humidity in development of tomato powdery mildew (Oidium lycopersici) in the glasshouse. European Journal of Plant Pathology, v.106, p.395-397, 2000.

Recebido em 17 de março de 2005 e aprovado em 21 de novembro de 2006 